Didaché: Journal of Christian Education

Vol. 1, No. 2 (2020): 91-116

journal.sttsimpson.ac.id/index.php/DJCE

e-ISSN: $2722-8584$

\title{
Kunci Keberhasilan Seorang Anak Dalam Pemaparan Alkitab
}

\author{
Astrid Maryam Yvonny Nainupu \& Ayang Emiyati \\ Sekolah Tinggi Teologi Simpson Ungaran \\ Email: aleviah.divani@gmail.com
}

\begin{abstract}
Every parent definitely wants the children to succeed in their life. However, most parents do not understand the true key of success. On the other hand, they are not able to accompany and educate their children to be success. The purpose of this study is to search the exposure of the Bible about the concept of success, the way a child raised by the parent or adults based on the examples from the Bible. The method used in this study is a literature review research and the exegesis of Bible. Based on the Bible success promised by God is a success in wealth and an ability to have wisdom needed to manage the daily problems. Besides, the important thing for a child to be success based on the exposure of the Holy Bible, is by reading, meditating and being careful to do everything written in the Scripture.
\end{abstract}

Keywords: success; children, bible

\begin{abstract}
Abstrak
Setiap orang tua pasti ingin agar anak - anaknya berhasil di dalam hidupnya. Tetapi belum tentu semua orang tua memahami kunci keberhasilan yang sejati. Di sisi lain, belum tentu juga semua orang tua dapat mendampingi anak - anak mereka dan mendidik mereka sehingga menjadi berhasil. Penelitian ini bertujuan meneliti pemaparan Alkitab tentang konsep keberhasilan, bagaimana seorang anak dapat berhasil dalam didikan orang tua atau orang dewasa lainnya berdasarkan contoh - contoh dari Alkitab. Metode yang dipakai dalam penulisan ini adalah penelitian studi pustaka dan eksegese Alkitab. Berdasarkan pemaparan Alkitab ditemukan bahwa keberhasilan yang dijanjikan Allah bagi umat-Nya adalah keberhasilan yang meliputi kesuksesan secara materi dan kemampuan untuk mendapatkan hikmat yang dibutuhkan dalam menangani masalah - masalah kehidupan. Selain itu kunci agar seorang anak dapat mencapai keberhasilan dalam pemaparan Alkitab adalah dengan membaca, merenungkan dan bertindak hati - hati sesuai yang dituliskan di dalam Firman Tuhan.
\end{abstract}

Kata kunci: keberhasilan; anak; Alkitab 


\section{Pendahuluan}

Setiap orang orang tua pasti mengharapkan dan berusaha semaksimal mungkin agar anak-anaknya dapat berhasil termasuk di dalamnya para orang tua Kristen. Bukan hal yang tabu jika orang Kristen pun berharap agar anaknya berhasil. Bahkan Alkitab sendiri berkali-kali menegaskan bahwa Allah menjamin keberhasilan umat-Nya dan Allah ingin agar umat-Nya berhasil. Di dalam Yosua 1:8 dengan jelas dikatakan bahwa Tuhan menjanjikan keberhasilan dan keberuntungan kepada Yosua. Woudstra (1981) mengatakan asuransi atau jaminan kesuksesan telah diberikan di dalam Yosua 1:7 dan ayat 8 merupakan konfirmasi peneguhan dari Tuhan. Di bagian lain, di dalam 2 Tawarikh 26:5 jelas dikatakan selama Zakharia mencari TUHAN, Allah membuat segala usahanya berhasil. Secara literal berdasarkan ayat ini ditemukan bahwa keberhasilan Zakharia adalah karena Tuhan yang membuat segala usahanya menjadi berhasil (Payne, 1988). Nehemia pun mengakui bahwa keberhasilannya adalah karenaTuhan yang membuatnya di dalam Nehemia 2:20. Di Dalam tafisran Full Life dikatakan berkaitan dengan Negemia 2:20, di dalam segala hal keberhasilan dimulai dengan Allah (Full Life: Penuntun Hidup Berkelimpahan, 2015). Dengan demikian jelas bahwa Allah menginginkan umat-Nya berhasil, menjanjikan keberhasilan bagi umat-Nya dan bahkan menyertai umat-Nya agar dapat mencapai keberhasilan tersebut karena hanya Allahlah sumber dari segala keberhasilan manusia.

Walaupun keberhasilan adalah bagian dari janji Allah kepada umat-Nya, tetapi usaha manusia juga sangat diperlukan agar keberhasilan itu dapat dicapai. Jelas bahwa tidak ada keberhasilan di luar Tuhan, tetapi juga bahwa tidak ada keberhasilan tanpa usaha. Alkitab berkata bahwa orang yang malas atau tidak mau berusaha di dalam hidupnya tidak akan mendapatkan apa-apa (Ams. 12:27). Menurut Clarke, ('Proverbs 12 Commentary - Adam Clarke Commentary', n.d.) karena teralu malas sehingga orang tersebut tidak berburu untuk mendapatkan mangsanya, bahkan tidak melakukan sesuatu supaya ia bisa makan. Selain itu Amsal 20:4 juga mengatakan bahwa orang yang malas tidak akan mendapatkan hasil pada musim menuai karena ia tidak membajak pada musim dingin. Menurut Henry (Matthew Henry Commentary, 2015) jelas bahwa orang yang malas dan hanya mencintai kenyamanan tidak akan mendapatkan apa-apa di dalam hidupnya. Jika ditarik kaitannya dengan keberhasilan seorang anak, tentu saja usaha dari anak tersebut sangat berpengaruh besar terhadap keberhasilannya, tetapi di sisi lain tak dapat dipungkiri bahwa ada pihak lain di 
luar diri sang anak yang juga harus berusaha dan menolong anak tersebut untuk dapat mencapai keberhasilannya.

Ada banyak orang di sekitar seorang anak dan kehidupannya yang dapat meninggalkan jejak yang baik bagi keberhasilan anak tersebut. Herlina menjelaskan peran orang tua seharusnya adalah yang utama dalam keberhasilan anaknya karena orang tualah yang harusnya meninggalkan warisan baik secara rohani, warisan berupa teladan kehidupan berupa etos kerja yang baik, warisan psikologis dan sosial (Herlina 2018, p.98). Alkitab juga menegaskan otoritas orang tua kepada anak-anak di dalam Efesus 6:1 yang mengatakan "Hai anakanak, taatilah orang tuamu di dalam Tuhan, karena haruslah demikian". Sehingga peran didikan orang tua kepada anak-anak sebagaimana prinsip pendidikan yang terkandung dalam ayat Efesus 6:1 yaitu (1) orang tua mengambil peran penting dalam pendidikan anak; (2) pendidikan kepada anak merupakan sebuah proses transfer pengetahuan dan penanaman nilai-nilai kehidupan (Wenas \& Darmawan, 2017). Orang tua mempunyai tugas mendidik anak-anak dengan peran yang penting atau utama dengan menjalankan proses transfer pengetahuan dan penanaman nilai-nilai kehidupan kepada anaknya.

Tetapi pada kenyataannya ada banyak anak-anak yang dibesarkan tanpa kehadiran secara nyata dari orang tuanya dan dengan sangat terpaksa harus dibesarkan oleh orang lain bahkan oleh orang tua asuh dalam sebuah yayasan tertentu. Selain itu, banyak juga anak yang dibesarkan oleh kakek dan neneknya. Penelitian Rahmwati (2015) menunjukkan bahwa anak usia 5-6 tahun jauh lebih mandiri dalam pengasuhan dari granparents-nya. Peran dari pengasuh akhirnya menjadi sama dengan orang tua yaitu memberi segala stimulasi yang dibutuhkan oleh anak agar mereka pun dapat berkembang maksimal (Pertiwi, 2014). Sejak bertahun-tahun yang lalu tuntutan untuk memenuhi kebutuhan keluarga mengharuskan ada banyak orang tua yang bekerja di luar rumah, secara khusus juga para ibu agar dapat memenuhi kebutuhan keluarganya. Ada banyak ibu yang setiap hari bergulat dengan monster rasa bersalah karena harus meninggalkan anaknya diasuh oleh orang lain sementara ia sendiri harus bekerja agar kebutuhan -kebutuhan hidup di rumah dapat tercukupi (West, 1994, p.120). Di sisi lain ada juga banyak ayah yang tidak hadir secara nyata di dalam masa perkembangan dan pertumbuhan anaknya dengan alasan ia harus lebih banyak fokus sebagai pencari nafkah di dalam keluarga sehingga tugas membesarkan anak lebih sering diserahkan kepada istri atau ibu (Pangaribuan, 2017). 
Mcdonald (1985) memberikan contoh kehidupan Daud di dalam Alkitab ketika menjelaskan tentang bagaimana anak-anak Daud menjadi gagal karena absennya kehadiran Daud dalam hidup mereka. Lebih lanjut Mcdonald mengatakan Daud adalah contoh seorang ayah yang disebut gagal dalam beberapa kasus kegagalan anaknya yang dicatat di dalam Alkitab. Harus diakui bahwa Daud adalah seorang pemimpin yang berhasil dalam mengurus kerajaannya karena Ia dapat mengumpulkan tentara, memerintah mereka, dan memimpin mereka mencapai kemenangan-kemenangan yang gilang gemilang. Ia telah membangun kota-kota, menulis puisi-puisi yang sangat berarti tapi ketika ia mati, dia meninggalkan sekelompok anak-anaknya yang menentang hampir segala hal yang berarti dan penting bagi dia (Gordon, 1985). Kesimpulannya, Daud adalah ayah yang tidak efektif dan berhasil Daud tidak berhasil berperan dengan baik sehingga anak-anaknya pun tidak dapat berhasil dalam hidup mereka. Daud adalah contoh seorang ayah yang berusaha matimatian demi kerajaannya, tetapi tidak efektif dalam mendidik semua anaknya.

Kenyataan yang lain adalah ada anak-anak juga harus menerima kenyataan bahwa orang tuanya tak bisa hadir secara fisik di dalam hidup mereka sehingga mereka harus bertumbuh besar dan melihat teladan baik dalam iman maupun dalam hal-hal yang lain justru dari kehidupan orang dewasa lainnya. Salah satu contoh yang ada di dalam Alkitab adalah Samuel. Sejak ia disapih ibunya, Samuel telah dititipkan kepada Imam Eli untuk tinggal di Bait Allah. Terlepas dari kelemahan Samuel di dalam urusan anak-anaknya yang ditolak oleh Umat Israel, seumur hidupnya Samuel menjadi berhasil sebagai seorang nabi yang terus memperkenankan hati Tuhan hingga hari terakhir hidupnya. Ternyata ia pun bisa berhasil walau ia tidak dididik di rumah oleh orang tuanya. Contoh lain adalah Yosua, tak pernah disebutkan di dalam Alkitab bagaimana masa kecilnya tetapi sejak masa mudanya ia telah ikut bersama-sama dengan Musa di dalam perjalanan selama 40 tahun di padang gurun, dan Alkitab menyebutkan janji keberhasilan itu diberikan Tuhan kepadanya. Dengan demikian jelas bahwa anak-anak yang besar tanpa didikan penuh dari ayah dan ibu pun dapat berhasil di dalam hidupnya.

Berdasarkan pendapat secara umum yang dalam hal ini di luar dari pandangan Kristen pun mengajarkan tentang pentingnya peran orang tua dalam keberhasilan dan kehidupan anaknya. Menurut Umar (2015) orang tua menentukan masa depan secara khusus keberhasilan anak-anaknya. Selain itu, dari sudut pembentukan karakter anak, orang tua juga memiliki peran yang 
besar. Menurut Permono (2013) lingkungan keluarga dalam hal ini orang tua dapat menjadi pola penting dalam pembudayaan karakter bangsa bagi anak dan generasi muda. Sementara itu dalam keluarga Kristen, peran orang tua dalam mendidik anak-anak tentang pendidikan Agama Kristen juga sangatla penting. Menurut Tafonao (2018) Pendidikan Agama Kristen dalam keluarga sangat penting diterapkan oleh orang tua di zaman sekarang. Jadi, peranan orang tua dalam mengasuh anak-anak sangatlah penting, bukan hanya anak belajar dan mengalami pertumbuhan di dalam keluarga, tetapi seluruh anggota keluarga dapat saling belajar dari yang lain melalui interaksi satu sama lain. Akan tetapi, semuanya itu tidak lepas dari keteladanan orang tua dalam keluarga. Tidak dapat dipungkiri bahwa orang tua mempunyai peran yang sangat signifikan dalam keberhasilan anak-anaknya.

Dengan demikian yang menjadi rumusan masalah dalam penelitian ini adalah jika peran orang tua begitu penting dalam mendidik anak-anak, apakah anak-anak hanya bisa berhasil jika dididik oleh orang tua saja? Apakah anakanak yang tidak dibesarkan orang tua, yang hanya dibesarkan oleh pengasuh dapat berhasil juga? Dan apa makna sesungguhnya dari keberhasilan itu dalam pemaparan Alkitab. Adapun tujuan dari penelitian ini adalah menemukan jawaban tentang makna keberhasilan berdasarkan prinsip Alkitab, menjelaskan cara mencapai keberhasilan yang sesuai dengan janji Tuhan di dalam Alkitab, memaparkan contoh-contoh di dalam Alkitab tentang anak-anak yang berhasil dalam hidupnya dan menarik kesimpulan pada akhirnya tentang apakah seorang anak tetap dapat berhasil walaupun tidak di bawah didikan langsung dari orang tuanya.

\section{Metode}

Metode yang dipakai di dalam penelitian ini adalah penelitian studi pustaka dan eksegese Alkitab. Objek penelitian ini adalah perspektif Alkitab tentang keberhasilan dan pendidikan anak. Studi secara literatur dilakukan oleh peneliti agar dapat menggali dan memahami hal-hal menyangkut kunci keberhasilan, peran orang tua dan orang dewasa lainnya dalam keberhasilan anak-anak dan contoh anak-anak yang berhasil di dalam Alkitab. Penelitian ini juga memanfaatkan prinsip-prinsip hermeneutika atau penafsiran Alkitab. Sumber-sumber yang dipakai di dalam penelitian ini adalah (1) Alkitab Terjemahan Baru ; (2) Bible Works Versi 7.0.012g tahun 2006 ; (3) kutipan Alkitab dalam Terjemahan Indonesia Baru diambil dari aplikasi Sabda (OLB versi 
Inodenesia) versi 4.13.02 dan (4) aplikasi My Sword Bible versi 9.4. Bahan-bahan penafsiran untuk ayat-ayat Alkitab yang menjadi referensi akan diambil dari buku-buku atau aplikasi penafsiran Alkitab.

\section{Hasil dan Pembahasan}

\section{Keberhasilan Menurut Pandangan Alkitab}

Sebagaimana telah diungkapkan dalam bagian pendahuluan, beberapa ayat di dalam Alkitab menegaskan bahwa Allah bukan saja menjanjikan keberhasilan bagi umat-Nya tetapi bahkan Allah pun menyertai umat-Nya sehingga dapat mencapai keberhasilan di dalam hidupnya. Salah satu ayat yang jelas berbicara tentang janji keberhasilan dari Allah ada di dalam Yosua 1:8 sehingga ayat inilah yang akan menjadi dasar pemaparan dari peneliti di dalam Yosua 1:8 (Alkitab, n.d.) dikatakan demikian:

Janganlah engkau lupa memperkatakan kitab Taurat ini, tetapi renungkanlah itu siang dan malam, supaya engkau bertindak hati-hati sesuai dengan segala yang tertulis di dalamnya, sebab dengan demikian perjalananmu akan berhasil dan engkau akan beruntung.

Ayat ini dengan sangat jelas menunjukkan bahwa jaminan keberhasilan dan keberuntungan itu bersumber dari Allah sendiri. Keberanian, harapan, akan kemenangan dan hikmat Yosua yang diperlukan untuk mencapai keberhasilan tergantung dari kehidupan Yosua yang memberi perhatian terus menerus dan mentaati firman (Tafsiran Alkitab Wycliffe, 2015). Allah berjanji kepada Yosua ketika Yosua sebagai pemimpin yang memimpin umat Israel masuk ke Kanaan sedang ragu untuk menjalankan tanggungjawab yang ditinggalkan Musa kepadanya. Dalam situasi yang demikian, Tuhan sendiri berkata bahwa ia pasti akan berhasil dan beruntung.

Apakah yang dimaksudkan dengan berhasil dan beruntung berdasarkan

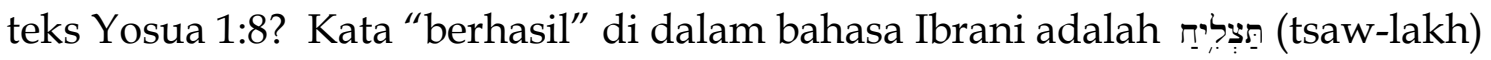
(Bible Works, 2006). Kata ini menggunakan bentuk Hiphil yang diterjemahkan "to make prosperous, to cause to thrive, causes to prosper". Sementara kata "beruntung" menggunakan kata (saw - kal) juga menggunakan bentuk Hiphil yang berarti "to look at, prosper". Dalam terjemahan dijelaskan juga makna yang lain dari kata ini dalam bentuk Hiphil selain dari keberuntungan (prosper) adalah to have insight, to act circumpspectly, act prudently, act wisely (My Sword Bible, n.d.). Dengan demikian kedua kata ini mempunyai makna yang hampir sama yaitu 
mengandung unsur berhasil dengan baik atau makmur. Tetapi di balik keberhasilan dan keberuntungan dalam arti harafiah tersebut juga terkandung makna bersikap bijaksana, memiliki pengertian yang bijak dan dilakukan dengan sangat hati-hati. Dengan demikian orang yang berhasil dan beruntung bukan saja menunjuk pada mereka yang makmur atau mendapatkan keuntungan secara harafiah, tetapi juga menunjuk pada situasi dimana seseorang mempunyai pengertian yang bijak, mampu bersikap bijaksana dalam situasi yang tepat dan berhati-hati di dalam hidupnya.

Sementara itu, kitab Mazmur juga mencatat hal yang senada dengan janji Tuhan di dalam Yosua 1:8. Mazmur 1:3 mengatakan:Ia seperti pohon, yang ditanam di tepi aliran air, yang menghasilkan buahnya pada musimnya, dan yang tidak layu daunnya; apa saja yang diperbuatnya berhasil." Ayat ini menunjukkan sebuah gambaran tentang keberhasilan yang diibaratkan seperti sebuah pohon yang ditanam di tepi aliran air, pohon yang menghasilkan buah pada musimnya. Kata berhasil di dalam ayat ini menggunakan kata (tsawlakh), kata yang sama yang digunakan di dalam Yosua 1:8. Menurut tafsiran Alkitab yang ditulis oleh Barth-Frommel dan Pareira (1984, p. 121), bagian terakhir dari ayat ketiga ini mungkin ditambahkan dari Yosua 1:8. Jika demikian maka dapat dikatakan bahwa makna keberhasilan dalam Yosua 1:8 sama dengan makna keberhasilan menurut Mazmur 1:3. Menurut Goleman (2001) dan Wijanarko (2018) anak yang berhasil adalah anak yang juga memiliki kecerdasan emosional dan spiritual. Oleh sebab itu jika dikaitkan dengan Mazmur 1:3 salah satu tanggung jawab orang tua agar anaknya berhasil menurut Wijanarko (2018) adalah mengajar mereka untuk bergaul dan memiliki hubungan pribadi dengan Tuhan melalui pembacaan firman Tuhan.

\section{Makna Keberhasilan Dalam Pemaparan Alkitab}

Berdasarkan ayat-ayat dari Mazmur 1:3 dan Yosua 1:8 dapat disimpulkan bahwa keberhasilan dan keberuntungan adalah kondisi dimana seseorang mencapai kesuksesan dalam arti harafiah misalnya memiliki pekerjaan dengan penghasilan yang baik atau karir yang bagus, tetapi jika hanya berhenti di situ maka itu bukanlah keberhasilan yang sejati. Keberhasilan yang sejati adalah ketika seseorang mempunya hikmat di dalam hidupnya. Dan disinilah letak tugas yang sesungguhnya dari pendidikan Kristen. Menurut Pazmino (1988) dan Santoso (2005) pendidikan Kristen merupakan upaya Ilahi dan manusiawi yang dilakukan secara sistematis dan berkesinambungan untuk mentransmisi 
pengetahuan, nilai-nilai, sikap dan ketrampilan serta tingkah laku yang konsisten dengan iman Kristen. Dengan jelas dapat dikatakan bahwa siapapun yang bertanggungjawab untuk mendidik anak-anak, baik di dalam keluarga Kristen maupun lembaga pendidikan Kristen haruslah mendidik mereka sesuai dengan kehendak Allah.

Alkitab di dalam Amsal 1:7 berkata "takut akan Tuhan adalah permulaan pengetahuan". Kata pengetahuan dalam Bahasa aslinya menggunakan kata דירָיעת yang berarti pengetahuan, persepsi, keahlian, pengertian, dan hikmat (My Sword Bible, n.d.). Selanjutnya Amsal 1:7 juga mengatakan bahwa orang bodoh adalah orang yang menghina hikmat dan didikan. Kata menghina (\%) berarti tidak menganggap sebagai sesuatu yang penting atau bahkan merasa jijik terhadap sesuatu yang merupakan lanjutan dari kata tersebut (My Sword Bible, n.d.). Sehingga menghina hikmat dan didikan berarti menganggap sepele hikmat dan didikan bahkan merasa jijik terhadap hikmat dan didikan. Menurut Jamieson ('Proverbs - Chapter 1 - Jamieson, Fausset, Brown Commentary on StudyLight.Org', n.d.) orang yang bodoh adalah orang yang berbeda dengan karakter dan pemerintahan Allah sehingga dapat disebut juga sebagai orang jahat. Jika orang bodoh adalah yang menghina hikmat dan didikan, maka orang yang berhikmat adalah orang yang mau dididik dan dalam hal ini dididik untuk takut kepada Tuhan. Hikmat diperoleh di dalam pendidikan yang benar. Dan pendidikan yang benar adalah pendidikan yang meletakkan dasar takut kepada Tuhan di dalamnya. Selanjutnya, Santoso (2005, p. 297) mengatakan bahwa hikmat adalah dimensi tertinggi dalam tahapan ilmu pengetahuan sebab ini berarti menerapkan pengetahuan dalam perspektif nilai kebenaran Ilahi. Jika seorang anak telah dididik untuk takut kepada Tuhan maka ia juga harus menerapkan pengetahuan tentang takut kepada Tuhan itu di dalam kehidupannya secara nyata. Dengan demikian dapat dikatakan bahwa orang yang berhasil membutuhkan usaha yang keras tetapi keberhasilan yang sejati hanya akan didapat oleh orang yang takut kepada Tuhan di dalam seluruh hidupnya. Sebagaimana Calvin mengatakan: "Keberhasilan hanya didapatkan dalam perkenanan ilahi"(Calvins Commentaries, 1993). Bagian lain dari Alkitab di dalam pengkhotbah 10:10 menyimpulkan bahwa hikmat adalah kunci dari keberhasilan, dan bertindak dengan hikmat adalah bagian dari keberhasilan itu sendiri (Siahaan, 2016). Kata sukses atau berhasil diterjemahkan oleh Singgih (2015) dan Siahaan (2016) sebagai "kepakaran" atau "menjadi ahli”. Oleh karena itu kesimpulan dari Siahaan bagian dari Pengkhotbah 10:10 dapat dimengerti 
bahwa hikmat memberikan keuntungan untuk menjadikan seseorang pakar atau ahli dalam bidang tertentu. Anak-anak yang ahli dalam bidang tertentu mungkin tidak mengalami pencapaian secara materi tetapi ia menghasilkan sesuatu dalam bidang pengetahuan atau akademis dan itupun adalah anak yang berhasil. Dengan demikian jelas menurut Alkitab definisi berhasil adalah mendapatkan hasil dari kerja keras dan mempunyai hikmat untuk bertindak bijaksana dalam segala situasi.

\section{Kunci Mendidik Anak Agar Berhasil}

Mendidik Mereka Untuk Merenungkan Firman Tuhan Siang dan Malam

Baik di dalam Yosua 1:8 dan Mazmur 1:3 disebutkan bahwa kunci dari keberhasilan yang pertama adalah merenungkan Firman Tuhan siang dan malam. Kata merenungkan dalam Bahasa Ibrani (יִ: Haga/mutter) mengandung arti mengulang-ulang dengan suara pelan (Gaebelein, 1984, p. 257). Sementara itu LXX memakai kata Meletao; merenungkan sambil bermeditasi dan latihan yang bisa didengar atau dilakukan oleh para orator.(Tafsiran Alkitab Wyclife Vol 1 Kejadian -Ester, 2011). Hal ini senada dengan apa yang dikatakan oleh BarthFrommel dan Pareira (1984). Kata merenungkan berarti mendaraskan atau mengaji artinya membacakan untuk diri sendiri dengan suara halus dan hal itu dilakukan siang dan malam artinya terus menerus (Barth-Frommel \& Pareira, 1984, p. 125). Kata Taurat (בתרוֹ) menunjuk pada "law of the Lord" yang berarti pengajaran, instruksi atau petunjuk yang berasal dari kitab suci yang pada waktu itu seringkali menunjuk pada buku hukum yang ditulis oleh Musa (Ul. 31:9-11).

Sejak usia sedini mungkin, anak-anak harus diajarkan untuk membaca Alkitab berulang-ulang dan merenungkannya. Anak-anak Yahudi sedini mungkin telah diajarkan untuk membaca dan merenungkan Taurat. Dalam buku Bimbing Anak Cinta Alkitab, Stanislius (2018) mengatakan bahwa sejak usia anak-anak Yahudi 5 tahun mereka sudah diajarkan untuk mempelajari Kitab Suci, usia 10 tahun mempelajari Mishnah, usia 13 tahun mempelajari perintahperintah dan usia 15 tahun mempelajari Talmud sebagaimana arahan dari perintah Tuhan di dalam Ulangan 6 yang biasa disebut sebagai Shema Israel. Pembelajaran Kitab Taurat mendapat tempat yang utama bagi orang tua Yahudi yang diteruskan kepada anak-anaknya secara terus menerus. Menurut Magdalena (2011) tujuan utama dari pendidikan anak Yahudi agar mereka 
bertumbuh di dalam firman Tuhan dan menyembah Tuhan dengan takut dan gentar.

Orang tua Kristen masa kini juga seharusnya meletakkan pembelajaran Alkitab sebagai yang utama bagi anak-anaknya bahkan sejak usia mereka masih sangat kecil. Perintah yang jelas diberikan kepada para orang tua di dalam firman adalah agar mendidik anak-anak di dalam takut akan Tuhan melanjutkan perintah di dalam ulangan 6 untuk terus menerus mengajarkan Taurat Tuhan. Terus menerus atau berulang-ulang di sini berarti tidak terhingga banyaknya bagi orang tua untuk melakukannya (Marbun, 2018). Menurut Darmawan (2019) metode yang dipakai dalam Ulangan 6 ini adalah memorisasi yang menggunakan berbagai media seperti mengikat tanda pada tangan dan membuat lambang di dahi serta mengikatnya pada tiang pintu rumah (Ul. 6:89). Makna dari Bahasa Ibrani yang digunakan dalam kata "mengajarkannya berulang-ulang" berarti mengasah. Ini juga merupakan suatu proses yang berlangsung terus menerus. Hal yang sama juga yang oleh Tuhan menjadi perintah untuk diperhatikan dan dilakukan oleh Yosua yaitu supaya Yosua memperkatakan Taurat Tuhan dan merenungkannya siang dan malam.

Sejak usia dini (maksimal 5 tahun) anak-anak sudah harus diajarkan untuk mengenal firman Tuhan. Suwardi (2007) mengatakan bahwa perilaku gemar membaca hendaknya ditumbuhkan sejak dini pada anak agar anak merasa tertarik dan memiliki minat yang tinggi terhadap membaca karena penanaman budaya baca akan lebih sulit diterapkan jika anak telah dewasa. Menurut Datu (2020) dengan membacakan firman Tuhan sejak anak masih kecil bahkan maka anak pasti akan lebih memiliki minat yang tinggi terhadap kebiasaan membaca firman Tuhan dan dengan demikian mereka akan bertumbuh di dalam iman. Dimulai dari orang tua yang membacakannya berulang-ulang kepada anaknya. Anak-anak mempelajari firman dengan melihat teladan orang tua yang juga mempelajari firman. Teladan orang tua dalam pembacaan dan perenungan firman akan menjadi teladan yang dasyat yang pasti juga dengan mudah diikuti oleh anak-anak. Amsal 22: 6 mengatakan "didiklah seorang anak menurut jalan yang patut baginya". Kata mendidik dalam bahasa Inggris berarti "to train, to dedicate"(My Sword Bible, n.d.). Anak harus dilatih menurut jalan yang patut baginya. Jalan yang patut baginya ini memiliki makna yang sama dalam Efesus 6:4b "tetapi didiklah mereka di dalam ajaran dan nasihat Tuhan"(Sutarni \& Hartatik, 2017). Dengan demikian jelas 
bahwa anak yang didik dengan nasihat Tuhan pasti akan terus ada di dalam jalan Tuhan dan mempermuliakan nama Tuhan.

\section{Mendidik Mereka Untuk Melakukan Firman Tuhan}

Kepada Yosua bukan saja diberikan perintah untuk membaca dan merenungkan firman Tuhan siang dan malam tetapi selanjutnya yang juga harus dilakukannya adalah bertindak hati-hati sesuai dengan firman Tuhan atau taurat yang telah dipelajari dan direnungkannya itu. Yosua diperintahkan untuk bertindak hati-hati (KJV: observe to do according to all that is written) sesuai dengan segaa perintah yang telah dituliskan. Bertindak hati-hati (Shamar: to keep, guard, give heed, observe). (My Sword Bible, n.d.)Artinya Firman Tuhan harus benar-benar menjadi perhatian dari Yosua, menjadi tuntunan semua perbuatan yang akan dilakukan oleh Yosua, menjadi rujukan yang selalu diperhatikan oleh Yosua dalam segala hal yang akan dilakukannya sebagai seorang pemimpin yang baru bagi umat Israel.

Di dalam perjalanannya Alkitab menunjukkan dan membuktikan bahwa Yosua benar mendapat penyertaan Tuhan ketika ia mengikuti perintah Tuhan. Menurut Jamieson ('Joshua - Chapter 1 - Jamieson, Fausset, Brown Commentary on StudyLight.Org', n.d.) perlu digarisbawahi bahwa kunci dari kemenangan Yosua adalah keteguhannya untuk melakukan perintah Tuhan. Misalnya dalam kisah yang tercatat di dalam Yosua 3 ketika Yosua dan orang-orang bersamanya hendak menyebrangi sungai Yordan. Di ayat 7-8 datang perintah Tuhan kepada Yosua tentang apa yang harus dilakukannya. Ayat 9 dan seterusnya menunjukkan bahwa Yosua mentaati firman Tuhan tersebut. Dan ayat 16 menunjukkan terjadinya mujizat Tuhan dimana air sungai Yordan berhenti mengalir dan bangsa itu dapat menyebrang dengan selamat. Walaupun semuanya dilakukan dengan tujuan untuk membesarkan nama Yosua di tengah Umat Israel, tetapi jelas bahwa Keberhasilan penyebrangan sungai Yordan terjadi karena Yosua menaati firman Tuhan ('Joshua - Chapter 3 - Coffman's Commentary of the New Testament on StudyLight.Org', n.d.). Hal yang sama terjadi pula dengan keruntuhan kota Yerikho di dalam catatan Yosua pasal 6. Ketika Yosua mentaati firman Tuhan, maka Yosua berhasil merebut kota Yerikho bahkan menyaksikan runtuhnya kota tersebut dengan mujizat Tuhan yang luar biasa. Pada kenyataannya bukan hal yang mudah bagi Yosua untuk taat karena cara yang diberikan Tuhan untuk menaklukkan Yerikho bukanlah cara yang umum dilakukan pada masa itu ('Joshua - Chapter 6 - Coffman's Commentary 
of the New Testament on StudyLight.Org', n.d.). Walau demikian, Yosua memilih untuk tetap taat dan melakukan perintah Tuhan. Dengan demikian dapat dikatakan bahwa kemenangan dan keberhasilan Yosua benar-benar ditentukan oleh ketaatanya kepada perintah Tuhan sebagaimana kehendak Tuhan yang telah disampaikan kepadanya sejak awal panggilan Tuhan kepadanya.

Sebagaimana janji dan perintah Allah kepada Yosua, maka perintah yang sama juga berlaku bagi anak-anak hari ini. Anak-anak yang berhasil adalah anak-anak yang melakukan firman Tuhan yang telah didengarnya setiap hari. Anak-anak harus mendengar firman setiap hari supaya mereka bisa bertindak hati-hati sesuai dengan firman yang tertulis di dalam Alkitab. Menurut Ramban (2020) anak-anak harus belajar seperti perintah Tuhan kepada Yosua yaitu membaca firman Tuhan dengan suara nyaring, bahkan menghafalkan firman Tuhan yang dibaca juga melakukan diskusi tentang firman Tuhan sehingga anak tidak hanya selalu mendengar cerita tentang firman Tuhan saja tetapi juga dilatih untuk memperkatakan firman Tuhan. Adalah tugas orang tua dan orang dewasa lainnya untuk mendampingi dan mengarahkan anak-anak agar mereka tahu mana perintah yang harus diikuti dan mana larangan yang harus dijauhi. Sejak sedini mungkin, bahkan sejak di dalam kandungan kepada anak udah harus diperkenalkan tentang firman Tuhan. Sebagaimana yang dikatakan oleh Yang (2018) dan Diana (2019) bahwa Mazmur 78:5-6 menekankan bahwa ada tugas untuk mendidik anak sehingga mengenal perintah atau taurat Allah dan mendidik mereka di dalam jalan yang benar sehingga mereka dapat hidup dengan taat.

\section{Contoh Anak Yang Gagal Di Dalam Alkitab}

Ayah dari Hofni dan Pinehas adalah seorang Imam. Sebagai seorang Imam, Eli adalah pemimpin rohani bagi umat Israel pada masa itu. Dan berdasarkan ketentuan Taurat kedua anaknya juga otomatis menjadi imam melanjutkan jabatan keimaman dari ayahnya. Sebagai Imam, otomatis mereka mendapatkan penghasilan dari umat Israel. Dalam hal ini jika umat Israel mempersembahkan korban, misalnya korban Penebus Salah maka Imamat 7 mengatakan bahwa mereka berhak memakan atau mendapatkan korban yang dipersembahkan tersebut. Tetapi ternyata keadaan yang baik tersebut tidak dibarengi dengan tingkah laku yang berkenan dari Hofni dan Pinehas. 
Dalam 1 Samuel 2:12-27 dengan sangat jelas digambarkan bagaimana tingkah laku yang sangat tidak menghormati Tuhan terus menerus dilakukan oleh Hofni dan Pinehas. Menurut Soesilo (2014) walaupun perbuatan mereka telah menjadi perbincangan diantara umat Israel, tetapi tetap saja Hofni dan Pinehas tidak mengindahkan peringatan dari Imam Eli ayahnya (ayat 22-25). Menurut Clarke ('1 Samuel 2 Commentary - Adam Clarke Commentary', n.d.), Hofni dan Penahas adalah anak-anak yang jahat, anak-anak yang suka hidup dalam kemewahan tetapi juga adalah anak-anak yang bebal. Sehingga pada akhirnya jelas di dalam ayat 27-38 Tuhan sendiri menyatakan murka dan penghukumannya kepada Hofni dan Pinehas. Jelas bahwa selain karena Hofni dan Pinehas adalah anak-anak yang bebal, ayahnya Imam Eli juga adalah seorang ayah yang lemah kepada anak-anaknya (Soesilo, 2014). Menurut Clarke ('1 Samuel 2 Commentary - Adam Clarke Commentary', n.d.), Eli tidak menggunakan otoritasnya sebagai ayah untuk mendisiplin anak-anaknya dengan tegas. Ia menegur mereka dengan keras kata Alkitab, tetap tidak cukup tega untuk menghukum mereka dengan tegas sehingga dalam ayat 29 bahkan Tuhan mengatakan bahwa Eli lebih takut kepada anak-anaknya ketimbang kepada Tuhan. Menurut Hickey (2004) dan Soesilo (2014) ada 4 hal penting dalam mendidik seorang anak yaitu otoritas, kasih sayang, persetujuan dan penerimaan. Dan dalam hal otoritas kepada anak-anak, Imam Eli kehilangan kendali otoritas atas mereka. Dia tidak menggunakan otoritasnya sebagai orang tua untuk mendisiplin anak-anaknya. Ia tidak menuntut anak-anaknya untuk menghormati Tuhan dan mendengarkan firman. Sehingga pada akhirnya ia kehilangan mereka pada hari yang sama sekaligus dan ia pun pada akhirnya meninggal dengan cara yang sia-sia. Coffman ('1 Samuel - Chapter 2 - Coffman's Commentary of the New Testament on StudyLight.Org', n.d.) mengatakan pada usia seperti Hofni dan Pinehas, juga dalam usia yang lanjut dari Imam Eli menerapkan otoritas merupakan sesuatu yang mustahil untuk dilakukan. Elia kehilangan kontrol atas anak-anaknya pada usianya yang telah lanjut (1 Sam. $2: 22)$.

Hofni dan Pinehas hanya meneruskan jabatan keimaman ayahnya tanpa mau menaati Perintah dari Tuhan yang memberikan kepada mereka posisi tersebut. Sebagai keturunan imam seharusnya mereka tahu taurat Tuhan dan melakukannya secara hati-hati. Tetapi ternyata mereka tidak menaati firman Tuhan sehingga pada akhirnya mereka malah binasa. Eli sebagai Imam justru tidak meneladankan keimaman yang benar kepada anak-anaknya. Hasibuan 
menyimpulkan Hofni dan Pinehas menjadi loba karena mereka juga mempunyai seorang ayah yang rakus (Hasibuan, n.d.).

\section{Contoh Anak-Anak Yang Berhasil Di Dalam Alkitab}

Timotius Dalam Didikan Nenek dan Ibunya

Menurut Magdalena (2011), Timotius mempunyai Life preparation untuk masa depannya karena didik oleh seoran nenek dan mama yang takut kepada Tuhan. Alkitab dengan jelas mengatakan di dalam II Timotius 3:15 bahwa iman Timotius timbul karena sejak kecil ia dididik dengan kebenaran Firman Tuhan. Henry (Matthew Henry Commentary, 2015) mengatakan Paulus berbicara mengenai Nenek dan ibu dari Timotius dengan rasa hormat yang besar sebagai wanita-wanita yang saleh dan bijak. iltulah sebabnya tidak heran bahwa sejak kecil Timotius telah mengenal Kitab Suci yang diajarkan oleh nenek dan ibunya. Kata "mengenal" diterjemahkan di dalam Bahasa Inggris sebagai "to see dan to know" (My Sword Bible, n.d.). Kata "oidas" untuk mengenal diterjemahkan di dalam Bahasa Inggris sebagai "know (about), be (intimately) acquainted with, stand in close relation, understanding, recognize, remember". (Bible Works, 2006) Sehingga dapat disimpulkan bahwa mengenal Alkitab di sini menunjukkan bahwa Timotius sejak kecil telah membaca Alkitab, merenungkannya sehingga mempunyai hubungan yang dekat dengan firman Tuhan dan mempunyai pemahaman tentang firman Tuhan. Inilah yang menjadi kunci keberhasilan Timotius di dalam hidup dan pelayanannya. Henry (Matthew Henry Commentary, 2015) mengatakan barangsiapa yang mempelajari segala sesuatu dari Tuhan dan yang mendapatkan jaminan-Nya di dalam hidup mereka harus mengetahui firman Tuhan sebagai pewahyuan Ilahi bagi mereka.

Kualifikasi yang ada di dalam diri Timotius yang menunjukkan keberhasilannya ditunjukkan di dalam Alkitab:

\section{Mempunyai Reputasi Yang Baik (Kis. 16:2)}

Dalam ayat ini dikatakan bahwa Timotius dikenal baik oleh saudarasaudara yng ada di Listra dan Ikonium. Kata dikenal baik dalam Bahasa aslinya ditulis "emartureito" yang ditrjemahkan dalam Bahasa Inggris "testify favourably, speak well". (Bible Works, 2006) Artinya ketika jemaat atau orang-orang di Listra dan Ikonium menceritakan tentang Timotius, mereka menyaksikan tentang halhal yang baik dan menyenangkan tentang dia. Tafsiran Wycliffe (Tafsiran Alkitab 
Wycliffe, 2015) mengatakan sejak kunjungan Paulus yang pertama, Timotius telah memperolah reputasi yag baik di kalangan orang percaya di Listra dan Ikonium. Jelas bahwa reputasi Timotius baik di tengah-tengah jemaat yang mengenalnya. Bahkan Henry (Matthew Henry Commentary, 2015) mengatakan perilakunya tidak bercela, tidak pernah terlibat dalam masalah besar dan juga seorang muda yang cemerlang.

\section{Setia dan Berani (1 Kor. 4 : 17)}

Paulus menuliskan pujiannya untuk Timotius ketika ia megirimkan surat kepada jemaat di Korintus. Paulus mengutus Timotius kepada jemaat di Korintus dan memperkenalkannya sebagai pengikut Kristus yang setia. Ada masalah di tengah jemaat Korintus dan figur Timotius yang setia itu cocok untuk hadir di tengah-tengah jemaat. Tugas Timotius adalah memberikan nasihat tentang bagaimana hidup di dalam Kristus Yesus sebagaimana yang selama ini diajarkan Paulus. Timotius dinilai kompeten oleh Paulus dalam hal kesetiaannya sehingga ia cocok untuk hadir di tengah jemaat Kristus yang sedang diombang ambingkan oleh berbagai pengajaran yang menyesatkan. Menurut Gill ('1 Corinthians - Chapter 4 - Verse 17 - The New John Gill Exposition of the Entire Bible on StudyLight.Org', n.d.) Paulus benar benar mengenal kualitas dari Timotius, ia benar-benar teruji, terbukti dan dapat dipercaya sebagai seorang yang setia kepada Kristus. Selanjutnya Wycliffe (Tafsiran Alkitab Wycliffe, 2015) mengatakan Timotius bertugas untuk memperingatkan mereka dan dengan demikian ia harus berani melakukan tugas itu. Paulus merekomendasikan Timotius dan menyebutnya sebagai seorang yang "setia”. Kata setia (pisto.n) dalam Bahasa Inggris diterjemahkan sebagai: trustworthy, faithful, dependable, inspiring trust or faith. (Bible Works, 2006) Dengan demikian dapat dikatakan bahwa Timotius adalah seorang yang dapat dipercaya, beriman, dapat diandalkan dan memberi inspirasi kepada jemaat di Korintus soal beriman atau percaya kepada Yesus.

Pada bagian lain dalam surat kepada Timotius di dalam 2 Timotius 1:5, Paulus juga mengungkapkan pujiannya kepada Timotius. Ia menyebut Timotius sebagai orang yang beriman. Gill ('2 Timothy - Chapter 1 - Verse 5 - The New John Gill Exposition of the Entire Bible on StudyLight.Org', n.d.) mengatakan dia sangat bersyukur karena Timotius memiliki hati yang tulus dan murni sebagai orang percaya yang sejati. Paulus memuji tentang betapa besarnya iman yang dimiliki oleh Timotius. Dan iman itu timbul karena pengenalan akan Allah yang 
diajarkan oleh Neneknya Louis dan ibunya Eunike. Paulus menyebut iman

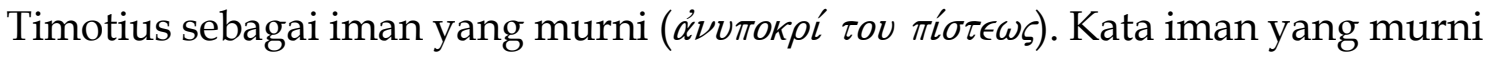
dalam Bahasa aslinya berarti "unfeigned, undisguised, sincere" (Bible Works, 2006). Iman itu bukan hanya tulus dan sungguh-sungguh tetapi juga terbukti melalui seluruh keberadaan Timotius. Melalui mama dan nenek yang mencintai firman lahirlah Timotius yang beriman dengan tulus kepada Tuhan.

Alkitab juga memberikan fakta yang membuktikan bahwa orang yang melakukan firman diberkati juga secara finansial dan memiliki hikmat yang dibutuhkan untuk hidupnya. Dan contoh tersebut adalah Salomo.

\section{Salomo Dalam Didikan Ayah dan Ibunya}

Dalam 1 Raja-raja 3:3 dikatakan "Dan Salomo menunjukkan kasihnya kepada TUHAN dengan hidup menurut ketetapan-ketetapan Daud, ayahnya..." Salomo menunjukkan kasihnya kepada Tuhan berdasarkan teladan yang diberikan Daud ayahnya. Hidup menurut dalam Bahasa aslinya dipakai kata

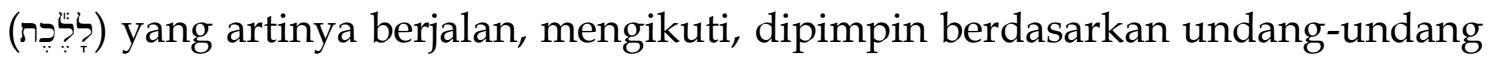
yang ditetapkan Daud ayahnya (Bible Works, 2006). Salomo melihat teladan iman seorang ayah yang tidak sempurna tetapi tetap mengikuti Tuhan sampai akhir hidupnya, dan itulah yang diteladani oleh Salomo. Dalam 1 Raja-raja 2:3-5, Daud berpesan kepada Salomo sebelum kematiannya supaya Salomo hidup menurut firman Tuhan yang tertulis dalam hukum Musa disertai dengan janji bahwa Tuhan pasti memberkati Salomo. Menurut Clarke ('1 Kings 2 Commentary Adam Clarke Commentary', n.d.) yang harus dilakukan Salomo adalah menjaga peraturan Tuhan, menjaga perintah Tuhan, menjaga hukum-hukum-Nya dan menjadi saksi-Nya. Termasuk apa yang harus dilakukan Salomo kepada musuhmusuh Daud atau kepada orang yang berjasa kepada Daud, dengan panjang lebar Daud pesankan itu bagi Salomo (1 Raj. 2:5-9). Daud meninggalkan warisan rohani melalui pengajaran tentang kebenaran Firman, apa yang dikehendaki Tuhan untuk dilakukan anaknya dengan sangat baik. Dan sebagai hasilnya maka Salomo mengalami keberhasilan. Di sisi lain, Batsyeba juga mempunyai peran yang sangat penting dalam pengangkatan Salomo menjadi Raja (1 Raj. 1:11-31). Sebagai seorang ibu dan istri, Batsyeba mengingatkan Daud akan sumpahnya untuk mengangkat Salomo sebagai raja karena pada waktu itu Adonia telah melakukan kudeta. Menurut Clarke ('1 Kings 1 Commentary - Adam Clarke Commentary', n.d.) Nabi Natan mengetahui bahwa Batsyeba dapat memberi pengaruh kepada Raja Daud atau dengan kata lain, Daud pasti akan 
mendengarkan apa yang dikatakan oleh Batsyeba. Batsyeba memainkan peran yang sangat krusial dalam kasus perebutan tahta ini dan karena Batsyebalah, Daud mengerti situasinya dan melakukan apa yang ditetapkan oleh Tuhan sendiri yaitu menjadikan Salomo sebagai raja menggantikan dia (Susanta, 2019)

\section{Keberhasilan Secara Finansial}

Alkitab menunjukkan tentang betapa banyaknya keberhasilan secara materi yang dapat diraih atau dicapai oleh Salomo. 1 Raja-raja pasal 4:21-34 menceritakan tentang betapa banyaknya harta yang dimiliki oleh Salomo karena perkenanan Tuhan atasnya. Dicatat di sana bahwa banyak bangsa membayar upeti kepadanya, bahkan takluk kepada salomo seumur hidupnya (ayat 21). Salomo mempunyai kuda yang tidak terhitung banyaknya (ayat 26). Bahkan makanan untuk kuda-kudanya pun sangat terjamin (ayat 27). Dan karena hikmatnya banyak orang datang untuk meminta nasihatnya dan ia pun mendapatkan harta benda dari situ (ayat 34). Menurut Clarke ('1 Kings 4 Commentary - Adam Clarke Commentary', n.d.) mereka datang untuk menjalin kerjasama dengan Salomo karena mendengar hikmatnya yang sangat luar biasa. 1 Raja - raja 7 mencatat tentang kemegahan istana Salomo, dilanjutkan dengan segala benda terbaik dan termahal dari logam yang dipersembahkan Salomo untuk bait suci yang dibangunnya (ayat 13-51). Menurut Clarke ('1 Kings 7 Commentary - Adam Clarke Commentary', n.d.) ayat 51 tetap menegaskan bahwa Salomo mengikuti segala yang ditetapkan Daud termasuk memasukkan barang-barang kudus dari Daud untuk rumah Tuhan. 1 Raja-raja 10:14-29 merangkum semua kekayaan yang dimiliki oleh Raja Salomo.

Alkitab mencatat Salomo mendapatkan banyak harta salah satu penyebabnya adalah karena hikmat yang dimilikinya. Biasanya seorang raja mendapatkan pemberian sebagai hasil jarahan perang, tetapi Ratu Syeba dalam 1 Raja - raja 10: 10 memberikan banyak harta kepada Salomo justru karena hikmat yang dari Tuhan ada padanya. Bahkan menurut Clarke ('1 Kings 10 Commentary - Adam Clarke Commentary', n.d., p. 10) ratu Syeba dengan tulus memuji Salomo dalam ayat yang ke-8 ketika ia menyebut berbahagia istri dan pegawai-pegawai Salomo. Menurut Siahaan (2016), ini adalah salah satu keuntungan dari seorang yang berhikmat. Tetapi jika kita merujuk lebih jauh jelas bahwa ini adalah akibat dari hubungannya dengan Tuhan yang diteladaninya dari Daud ayahnya. Karena jelas Tuhan sendiri berjanji bahwa kepada Salomo akan diberikan juga kekayaan dalam hal ini harta benda dalam 
ayat 13. Selain itu menurut Clarke ('1 Kings 3 Commentary - Adam Clarke Commentary', n.d., p. 3) Salomo akan mempunyai kapasitas yang luas dalam hal mengetahui segala perkara, kekuasaan juga kemakmuran sebagai janji Tuhan untuknya. Dari sini jelas tak dapat dipungkiri bahwa ketika Salomo mengikuti teladan Daud untuk terus beribadah kepada Tuhan dan menaati firman, dia tahu untuk meminta apa yang tepat kepada Tuhan yaitu hikmat dan sebagai bonusnya segala harta benda juga menjadi miliknya.

\section{Keberhasilan Dalam Sudut Pandang Memiliki Hikmat}

1 Raja-raja 3:16-28 mengisahkan tentang bagaimana Salomo berhasil memutuskan sebuah keputusan yang sangat berhikmat dalam kisah perebutan anak antara dua orang perempuan yang tinggal bersama. Menurut Barne ('1 Kings 3 Commentary - Albert Barnes' Notes on the Whole Bible', n.d.) dalam Ayat ke-28 dengan jelas dikatakan di sana bahwa ketika keputusan yang berhikmat itu ditetapkan, maka umat Israel menjadi takut kepada raja sebab jelas bahwa hikmat Allahlah yang ada padanya. Kata "menjadi takut" kepada raja digunakan dalam bentuk imperfect yaitu ויר yang berarti menunjukkan sikap hormat atau takjub kepada Raja Salomo (Bible Works, 2006). Lebih lanjut dalam 1 Raja-raja 5:12 dikatakan bahwa karena hikmatnya maka salomo dapat membawa perdamaian dalam hubungan kerjasamanya dengan Hiram. Di dalam 1 Raja-raja 10 juga diceritakan tentang takjubnya Ratu Syeba ketika melihat kepintaran Salomo dalam menjawab teka-tekinya (ayat 1), dan bagaimana pengaturan yang sangat teratur dan tepat di dalam rumah dan kerajaan Salomo atas makanan di mejanya, cara duduk pegawainya, cara berpakaian dan melayani dan bahkan ibadahnya kepada Tuhan. Dikatakan Ratu Syeba menjadi tercengang (ayat 5). Kata tercengang di sini menunjukkan kondisi dimana Ratu Syeba seperti kehilangan rohnya atau dalam pengertian dia kehilangan kata-kata untuk diucapkan.(My Sword Bible, n.d.) Sehingga Ratu Syeba mengucapkan pujiannya secara langsung kepada Salomo tentang hikmatnya itu. Barne ('1 Kings 10 Commentary - Albert Barnes' Notes on the Whole Bible', n.d.) mengatakan ucapan dalam ayat ke-9 ketika Ratu Syeba mengatakan Terpujilah Allahmu bukan hanya merupakan pengakuan tentang seorang dewa secara lokal, tetapi lebih kepada pengakuan tentang Allah Israel yang kekuasaan-Nya besar. Siahaan menulis hikmat yang dimiliki Salomo menjadi atribut yang membawa Salomo kepada kejayaan dan achievment dalam hidupnya (Siahaan, 2016). Orang yang mempunyai hubungan dengan Tuhan dalam hal ini takut akan Tuhan, 
anak-anak yang dididik dengan dasar firman Tuhan akan memperoleh hikmat di dalam hidupnya karena Amsal 1:7 mengatakan takut akan Tuhan adalah permulaan hikmat dan pengetahuan. Menurut Barne ('Proverbs 1 Commentary - Albert Barnes' Notes on the Whole Bible', n.d.) hidup yang berhikmat dimulai dari sikap yang kagum dan hormat kepada Tuhan. Salomo mendapatkan hikmat bukan hanya karena ia memintanya kepada Tuhan tetapi juga selanjutnya karena dia menghormati Tuhan dalam pemerintahannya sebagai raja.

\section{Anak-Anak Dalam Didikan Orang Dewasa Lainnya}

Di dalam Alkitab juga dikisahkan tentang kehidupan Nabi Samuel yang justru tinggal bersama dengan Imam Eli tetapi ia menjadi seorang nabi yang berkenan kepada Tuhan. Dalam 1 Samuel 1 diceritakan tentang bagaimana riwayat hidupnya karena ibunya yang sangat mengharapkan seorang anak sehingga akhirnya berdoa dan menangis di rumah Tuhan dan akhirnya dipikir gila oleh Imam Eli. Pada akhirnya Tuhan menjawab doa ibunya dan memberikan Samuel dalam keluarga Elkana dan Hana. Hana kemudian mempersembahkan Samuel untuk hidup dan menjadi abdi Allah yang tinggal bersama Imam Eli (1 Sam. 2 :11). Samuel ada di bawah pengawasan imam Eli. Dalam Bahasa aslinya menggunakan istilah אתי־ּנִ yang berarti menjadi mata bajak yang diasah oleh Imam Eli. (Bible Works, 2006) Jadi tujuan Hana menitipkan Samuel pada Eli adalah supaya Eli mengajarkan Firman kepada Samuel sehingga Samuel pun siap melayani Tuhan pada akhirnya. Menurut Bridgeway Bible Commentary ('1 Samuel 2 Commentary - Bridgeway Bible Commentary', n.d.) ini adalah cara ilahi dari Tuhan untuk mempersiapkan Samuel sebagai penerus dari Imam Eli.

Tidak banyak kisah tentang didikan Eli kepada Samuel tetapi jelas di dalam 1 Samuel 2:12-26 ketika Alkitab menceritakan tentang kejahatan dari anakanak Eli, dalam ayat 26 dikatakan bahwa Samuel yang masih muda itu semakin besar dan semakin disukai, baik di hadapan Allah dan di hadapan manusia. Samuel bertumbuh menjadi anak yang disukai (ㄱำㄱำ) yang juga bermakna bahwa hidupnya bernilai, layak dan membawa perkenanan bukan hanya di hadapan Allah tetapi juga manusia.(Bible Works, 2006) Tidak banyak pernyataan Alkitab tentang bagaimana Imam Eli mendidik Samuel, tetapi sekali lagi dalam 1 Samuel 3:1 dikatakan bahwa Samuel menjadi pelayan Tuhan di bawah pengawasan imam Eli walaupun pada masa itu firman atau pun penglihatan sangat jarang. Lebih lanjut dikatakan bahwa Imam Eli ternyata memiliki kepekaan bahwa Tuhanlah yang berbicara kepada Samuel setelah 2 kali sebelumnya Eli pun 
belum memahaminya. Walaupun Samuel belum pernah mendengar firman sebelumnya (1 Sam. 3:7), walau tentunya dia belajar tentang tata cara mempersembahkan korban dan beribadah di Bait Allah bersama dengan Imam Eli, tetapi Tuhan langsung berbicara kepadanya secara jelas (1 Sam. 3:11-14). 1 Samuel 3 kemudian ditutup dengan penampakan diri Tuhan kepada Samuel di Silo, setelah sebelumnya di ayat 19 dikatakan sekali lagi bahwa Samuel makin besar dan Tuhan menyertai dia dan tidak ada satu pun dari firman-Nya yang dibiarkan-Nya gugur. Samuel adalah seorang nabi yang diperintahkan Tuhan untuk menyampaikan firman kepada umat Allah (1 Sam. 3:20-21), ia juga adalah seorang hakim bagi umat Israel (1 Sam. 7:15), ia bahkan juga seorang imam yang dalam 1 Samuel 7:9 dikatakan ia mempersembahkan korban bakaran kepada Allah ('1 Samuel 3 Commentary - Bridgeway Bible Commentary', n.d.). Artinya semua yang difirmankan Tuhan melalui Samuel selalu digenapi atau terjadi dalam kapasitasnya sebagai Nabi, Hakim dan Imam. Itulah sebabnya semua umat Israel mengakui dia sebagai nabi Tuhan (ayat 20).

Samuel hanya berada di bawah pengawasan Imam Eli di Bait Allah, dia jauh dari ayahnya apalagi ibunya yang selalu berdoa dan memintanya kepada Tuhan. Menurut Clarke ('1 Samuel 3 Commentary - Adam Clarke Commentary', n.d.), Samuel berada di bawah pengawasan Imam Eli untuk melayani di Bait Allah (Tabernakel), di bawah perintah langsung dari Imam Eli dan salah satu tugasnya antara lain membuka pintu Bait Allah (1 Sam. 3:15). Dia bahkan berada di bawah pengawasan seorang imam yang tidak sempurna, bahkan jahat kelakuannya, tetapi firman Tuhan yang datang kepadanya ditaatinya dan menyebabkan dia memperkenankan Tuhan dan bahkan disukai oleh Umat Israel selama masanya menjadi seorang Nabi. Dalam usia yang masih sangat belia kirakira 12-13 tahun, kepada Samuel Tuhan membukakan apa yang menjadi kehendak-Nya secara khusus yang berkaitan dengan kehidupan Eli dan anakanaknya.('1 Samuel 3 Commentary - Bridgeway Bible Commentary', n.d.) Ia bahkan dipakai Tuhan mengurapi 2 raja di Israel yaitu Raja Saul dan Raja Daud. Anak-anak yang tidak berada di bawah didikan ayah dan ibunya, ketika berjumpa dengan firman di dalam hidupnya, pasti akan mengalami hidup yang diberkati. Dalam hal ini berkat bagi Samuel adalah dia diperkenan Allah dan disukai manusia. Sepanjang hidupnya Tuhan berkenan memakainya. Dengan demikian, walau tidak dididik langsung oleh ayah dan ibunya, seorang anak tetap dapat menjadi berhasil di dalam hidupnya asalkan dia berjumpa dengan Tuhan dan firman-Nya itu sendiri. 


\section{Kesimpulan}

Dari pembahasan di atas kita dapat menyimpulkan bahwa keberhasilan seorang anak baik itu secara materi, secara spiritual dalam hal mendapatkan hikmat untuk hidupnya, dan mendapatkan perkenanan Allah juga mempunyai karakter yang disukai dan pelayanan yang tulus adalah hasil dari pergaulannya dengan firman. Sejak awal tanggung jawab mendidik anak-anak diberikan oleh Allah kepada orang tua. Dengan demikian seharusnya orang tualah yang paling berperan dalam mendidik anak-anak sesuai dengan perintah Tuhan. Tetapi pada kenyataannya tidak selalu seorang anak tinggal dan dididik oleh orang tuanya sehingga berdasarkan pembahasan di atas ditemukan bahwa pada akhirnya siapapun yang tinggal dan mendidiknya, entahkah ayah dan ibunya, ataukah hanya salah satu saja, bahkan sekalipun dibesarkan oleh orang lain baik keluarganya atau bukan, asalkan dia dibesarkan dalam firman, dididik untuk melakukan firman pasti ia akan berhasil sesuai janji firman Tuhan. Dengan demikian seharusnya orang tualah yang mendidik anak-anak berdasarkan perintah firman agar mereka menjadi berhasil, tetapi jikalau hal tersebut tidak dapat dilakukan oleh orang tua maka seorang anak tetap dapat berhasil di dalam hidupnya asalkan kepadanya diajarkan untuk membaca, merenungkan dan bertindak hati-hati sesuai dengan firman Tuhan. Jadi yang perlu dilakukan orang tua atau orang dewasa lainnya yang kepada mereka diberikan tanggungjawab untuk mendidik anak-anak adalah mengajarkan firman kepada mereka. Yang perlu dilakukan anak-anak supaya berhasil dalam hidupnya adalah bertindak hati-hati sesuai dengan firman yang telah mereka baca dan renungkan. Sebaliknya, jika seorang anak tidak dibesarkan di dalam firman, tidak peduli mereka besar dalam didikan ayah dan ibunya yang bahkan adalah Imam atau hamba Tuhan, tetapi ketika mereka tidak hidup menurut firman, tidak ditegur berdasarkan firman, tidak diajar untuk takut akan Tuhan maka pasti ia akan gagal di dalam hidupnya. Bahkan yang lebih tragis adalah mendapatkan hukuman Tuhan. Oleh karena itu kepada setiap orang tua dan orang dewasa, ada tugas yang Tuhan berikan untuk mendidik anak-anak, entah anak sendiri ataupun anak-anak lain yang Tuhan titipkan supaya mereka belajar firman dan melakukannya dalam kehidupan sehari-hari. 


\section{Rujukan}

1 Kings 1 Commentary-Adam Clarke Commentary. (n.d.). Retrieved 8 December 2020, from StudyLight.org website: //www.studylight.org/commentaries/acc/1-kings-1.html

1 Kings 2 Commentary-Adam Clarke Commentary. (n.d.). Retrieved 8 December 2020, from StudyLight.org website: //www.studylight.org/commentaries/acc/1-kings-2.html

1 Kings 3 Commentary-Adam Clarke Commentary. (n.d.). Retrieved 8 December 2020, from StudyLight.org website: //www.studylight.org/commentaries/acc/1-kings-3.html

1 Kings 3 Commentary-Albert Barnes' Notes on the Whole Bible. (n.d.). Retrieved 8 December 2020, from StudyLight.org website: //www.studylight.org/commentaries/bnb/1-kings-3.html

1 Kings 4 Commentary-Adam Clarke Commentary. (n.d.). Retrieved 8 December 2020, from StudyLight.org website: //www.studylight.org/commentaries/acc/1-kings-4.html

1 Kings 7 Commentary-Adam Clarke Commentary. (n.d.). Retrieved 8 December 2020, from StudyLight.org website: //www.studylight.org/commentaries/acc/1-kings-7.html

1 Kings 10 Commentary-Adam Clarke Commentary. (n.d.). Retrieved 8 December 2020, from StudyLight.org website: //www.studylight.org/commentaries/acc/1-kings-10.html

1 Kings 10 Commentary-Albert Barnes' Notes on the Whole Bible. (n.d.). Retrieved 8 December 2020, from StudyLight.org website: //www.studylight.org/commentaries/bnb/1-kings-10.html

1 Samuel 2 Commentary-Adam Clarke Commentary. (n.d.). Retrieved 8 December 2020, from StudyLight.org website: //www.studylight.org/commentaries/acc/1-samuel-2.html

1 Samuel 2 Commentary-Bridgeway Bible Commentary. (n.d.). Retrieved 8 December 2020, from StudyLight.org website: //www.studylight.org/commentaries/bbc/1-samuel-2.html

1 Samuel 3 Commentary-Adam Clarke Commentary. (n.d.). Retrieved 8 December 2020, from StudyLight.org website: //www.studylight.org/commentaries/acc/1-samuel-3.html 
1 Samuel 3 Commentary-Bridgeway Bible Commentary. (n.d.). Retrieved 8 December 2020, from StudyLight.org website: //www.studylight.org/commentaries/bbc/1-samuel-3.html

1 Corinthians-Chapter 4-Verse 17-The New John Gill Exposition of the Entire Bible on StudyLight.org. (n.d.). Retrieved 4 December 2020, from https://classic.studylight.org/com/geb/view.cgi?book=1co\&chapter $=0$ 04\&verse $=017$

1 Samuel-Chapter 2-Coffman's Commentary of the New Testament on StudyLight.org. (n.d.). Retrieved 4 December 2020, from https://classic.studylight.org/com/bcc/view.cgi?book=1sa\&chapter $=00$ 2

2 Timothy-Chapter 1-Verse 5-The New John Gill Exposition of the Entire Bible on StudyLight.org. (n.d.). Retrieved 4 December 2020, from https://classic.studylight.org/com/geb/view.cgi?book=2ti\&chapter $=00$ $1 \&$ verse $=005$

Alkitab (Version Terjemahan Baru). (n.d.).

Barth-Frommel, M.-C., \& Pareira, B. A. (1984). Tafsiran Alkitab Mazmur 1-41. Jakarta: Gunung Mulia.

Bible works. (2006).

Calvins Commentaries. (1993). Michigan: Baker Book House.

Darmawan, I. P. A. (2019). Pembelajaran Memorisasi Dalam Ulangan 6:6-9. EPIGRAPHE: Jurnal Teologi Dan Pelayanan Kristiani, 3(1), 21-27. https://doi.org/10.33991/epigraphe.v3i1.50

Datu, M. (2020). Meningkatkan Minat Anak Sekolah Minggu Untuk Membaca Alkitab Di Era Globalisasi. OSF Preprints. https://doi.org/10.31219/osf.io/rfky9

Diana, R. (2019). Prinsip Teologi Kristen Pendidikan Orang tua terhadap Anak di Era Revolusi Industri 4.0. BIA': Jurnal Teologi Dan Pendidikan Kristen Kontekstual, 2(1), 27-39. https:// doi.org/10.34307/b.v2i1.79

ENNI RAHMAWATI, 1601411015. (2015). PERBEDAAN KEMANDIRIAN ANAK USIA 5-6 TAHUN DITINJAU DARI SUBYEK PENGASUH (ORANGTUA DAN GRANDPARENT) DI TK KARTINI 1 DAN TK KARTINI 2 WONOKETINGAL KECAMATAN KARANGANYAR KABUPATEN DEMAK (Other, UNIVERSITAS NEGERI SEMARANG). UNIVERSITAS NEGERI SEMARANG. Retrieved from http:/ / lib.unnes.ac.id/22608/

Full Life: Penuntun Hidup berkelimpahan (Version 1.3.5). (2015). Yayasan Lembaga Sabda. 
Gaebelein, F. E. (1984). The Expositors Bible Commentary (Vol. 8). Grand Rapids, Michigan: Zondervan Publishing House.

Goleman, D. (2001). Emotional Intelligence Untuk Mencapai Puncak Prestasi. Jakarta: Gramedia Pustaka Utama.

Gordon, M. (1985). Menjadi Ayah Idaman. Jakarta: BPK Gunung Mulia.

Hasibuan, N. (n.d.). SHEMA ISRAEL DAN IMPLEMENTASINYA DALAM PENDIDIKAN KELUARGA KRISTEN DI GBI SUMBER SARI BANDUNG. Https://Osf.Io/Preprints/Inarxiv/39rbx/Download.

Herlina, H. (2018). ANAK CUCUNYA TIDAK AKAN MEMINTA-MINTA PARENTING DAN GRANDPARENTING. PNEUMATIKOS | Jurnal Teologi STT STAPIN, 8(2), 97-108.

Hickey, M. (2004). Membangun Masa Depan Keluarga Yang Lebih Baik. Semarang: Media Injil Kerajaan.

Joshua - Chapter 1-Jamieson, Fausset, Brown Commentary on StudyLight.org. (n.d.). Retrieved 4 December 2020, from https://classic.studylight.org/com/jfb/view.cgi?book=jos\&chapter $=001$ Joshua-Chapter 3-Coffman's Commentary of the New Testament on StudyLight.org. (n.d.). Retrieved 4 December 2020, from https://classic.studylight.org/com/bcc/view.cgi?book=jos\&chapter=00 3

Joshua-Chapter 6-Coffman's Commentary of the New Testament on StudyLight.org. (n.d.). Retrieved 4 December 2020, from https://classic.studylight.org/com/bcc/view.cgi?book=jos\&chapter $=00$ 6

Marbun, P. (2018). MENGAGAS PENDIDKAN KARAKTER. Edukasi: Jurnal Pendidikan Agama Kristen, 10(1). Retrieved from http:// sttbi.ac.id/journal/index.php/edukasi/article/view/58

Matthew Henry Commentary (Version 1.3.5). (2015). Yayasan Lembaga Sabda.

My Sword Bible (Version 9.4). (n.d.).

Pangaribuan, W. (2017). METODE PENDIDIKAN BERKARAKTER OLEH AYAH PADA ANAK UNTUK KEBERHASILAN ANAK DISEKOLAH DAN DIPERKERJAAN. GENERASI KAMPUS, 5(1). Retrieved from https://jurnal.unimed.ac.id/2012/index.php/gk/article/view/7216

Payne, J. B. (1988). The Expositor's Bible Commentary: $1 \mathcal{E} 2$ Chronicles. Grand Rapids, Michigan: Zondervan Corporation. 
Pazmino, Robert. w. (1988). Foundational Issues in Christian Education. Grand Rapids : Michigan: Baker.

Permono, H. (2013). Peran Orangtua dalam Optimalisasi Tumbuh Kembang Anak untuk Membangun Karakter Anak Usia Dini. Prosiding Seminar Nasional Psikologi, Tema: Parenting: Optimalisasi Peran Orang Tua Dalam Pendidikan Karakter Bangsa. Presented at the Seminar Nasional Psikologi, Surakarta. Retrieved from http:// publikasiilmiah.ums.ac.id/handle/11617/3994

Pertiwi, S. (2014). POLA PENGASUHAN UNTUK MENGEMBANGKAN KARAKTER ANAK (STUDI KASUS DI YAYASAN TUNAS RAJAWALI KOTA SEMARANG). Journal of Nonformal Education and Community Empowerment, 3(1). Retrieved from https://journal.unnes.ac.id/sju/index.php/jnfc/article/view/3921

Proverbs 1 Commentary-Albert Barnes' Notes on the Whole Bible. (n.d.). Retrieved 8 December 2020, from StudyLight.org website: //www.studylight.org/commentaries/bnb/proverbs-1.html

Proverbs 12 Commentary-Adam Clarke Commentary. (n.d.). Retrieved 8 December 2020, from StudyLight.org website: //www.studylight.org/commentaries/acc/proverbs-12.html

Proverbs-Chapter 1-Jamieson, Fausset, Brown Commentary on StudyLight.org. (n.d.). Retrieved 4 December 2020, from https://classic.studylight.org/com/jfb/view.cgi?book=pr\&chapter=001 Ramban, Y. (2020). Implementasi pendidikan iman. OSF Preprints. https://doi.org/10.31219/osf.io/fvm8a

Santoso, M. P. (2005). Karakteristik Pendidikan Kristen. 15.

Santoso, P. M. (2011). Pola Alkitabiah Pendidikan Anak 7-12 Tahun yang Efektif untuk Pembentukan Karakter Pemimpin-Hamba di Seminari Anak 'Pelangi Kristus'. Veritas: Jurnal Teologi dan Pelayanan, 12(1), 39-60. https://doi.org/10.36421/veritas.v12i1.239

Siahaan, H. E. R. (2016). Hikmat Sebagai Implikasi Pendidikan Kristiani: Refleksi 1 Raja-raja 3:1-15. DUNAMIS: Jurnal Teologi dan Pendidikan Kristiani, 1(1), 15-30. https://doi.org/10.30648/dun.v1i1.99

Singgih, E. G. (2015). Hidup Di Bawah Bayang-Bayang Maut. Jakarta: BPK Gunung Mulia. 
Soesilo, Y. (2014). KELUARGA ELI DALAM 1 SAMUEL 2:11-36: SUATU EVALUASI PENDIDIKAN KRISTEN DALAM KELUARGA HAMBA TUHAN. Jurnal Antusias, 3(5), 136-146.

Stanislaus, S. (2018). Bimbing Anak Cinta Alkitab. Yogyakarta: Kanisius.

susanta, Y. K. (2019). Orang Kristen dan Politik: Belajar dari Kasus Salomo dan Adonia dalam Persaingan Menuju Takhta. Dunamis, 4 no 1.

Sutarni, N., \& Hartatik. (2017). Peranan Orang Tua Dalam Mendidik Anak Menurut Amsal 22:6 Terhadap Perilaku Sosial-Ekspresif Remaja. Jurnal Penabiblos: Pendidikan Agama Kristen, Musik Gerejawi, Teologi-Konseling Kristen, 16, 56-75.

Suwardi. (2007). Ciptakan Budaya Membaca Sejak Dini.

Tafonao, T. (2018). PERAN PENDIDIKAN AGAMA KRISTEN DALAM KELUARGA TERHADAP PERILAKU ANAK. Edudikara: Jurnal Pendidikan Dan Pembelajaran, 3(2), 121-133. https://doi.org/10.32585/edudikara.v3i2.92

Tafsiran Alkitab Wyclife Vol 1 Kejadian -Ester. (2011). Malang: Gandum Mas.

Tafsiran Alkitab Wycliffe (Version 1.3.5). (2015). Yayasan Lembaga Sabda.

Umar, M. (2015). Peranan Orang Tua Dalam Peningkatan Prestasi Belajar Anak. JURNAL EDUKASI: Jurnal Bimbingan Konseling, 1(1), 20-28. https://doi.org/10.22373/je.v1i1.315

Wenas, M. L., \& Darmawan, I. P. A. (2017). Siginifikasi Pendidikan Anak Dalam Perspektif Alkitab. Evangelikal: Jurnal Teologi Injili dan Pembinaan Warga Jemaat, 1(2), 118-128.

West, S. (1994). Mengatasi Problema Wanita Karier. Malang: Gandum Mas. WIJANARKO, D. J. (2018). Mendidik Anak Dengan Hati. Happy Holy Kids. Woudstra, M. (1981). The New International Commentary on The Old Testament: The Book of Joshua. Grand Rapids, Michigan: Wm. B. Eerdmans Publishing Co. Yang, F. (2018). Pendidikan Kristen. Surabaya: Momentum. 